\title{
Representaciones sociales frente a las sustancias psicoactivas desde un enfoque étnico-racial y de género. Estudio exploratorio, Universidad del Valle, Colombia ${ }^{1}$
}

\author{
Social representations regarding psychoactive substances from \\ an ethnic - racial and gender approach. Exploratory study, \\ Universidad del Valle, Colombia
}

\author{
María del Pilar Blanco Echeverry*
}

\section{Resumen}

El artículo es producto de una investigación acerca de las tendencias de consumo y representaciones sociales (RS) sobre las Sustancias Psicoactivas (SPA) por parte de estudiantes de la sede Norte del Cauca (NC) de la Universidad del Valle, Colombia. La investigación se realizó con 298 estudiantes -mujeres y hombres-. Una encuesta permitió caracterizar el consumo de SPA en el campus universitario. Las herramientas cualitativas permitieron captar percepciones e imágenes respecto al consumo de SPA. Si bien es cierto que este grupo de estudiantes no representan a toda la juventud del $\mathrm{NC}$, los hallazgos arrojaron pistas interesantes para comprender el consumo de SPA desde las representaciones sociales construidas a partir de su condición de hombre, mujer, afro descendiente o indígena, proyectándose en los discursos diferenciales captados a lo largo de la investigación. Miradas de gran utilidad para plantear a futuro estrategias diferenciadas de intervención que posibiliten una real inclusión en los procesos de prevención y mitigación del consumo.

${ }^{1}$ Este artículo es resultado de la investigación titulada: Tendencias de consumo y representaciones sociales frente a las Sustancias Psicoactivas desde un enfoque étnicoracial y de género: Estudio exploratorio con las y los estudiantes de la sede Norte del Cauca. Universidad del Valle, 2013 realizada en el marco de la "Convocatoria sedes regionales 2012 de la Vicerrectoría de Investigaciones de la Universidad del Valle.

* Trabajadora social y Magíster en Sociología de la Universidad del Valle. Docente de Trabajo Social, sede norte del Cauca, Universidad del Valle, Colombia. Correo Electrónico: maria.blanco@correounivalle.edu.co

Recibido: 9 de Marzo de 2017 Aprobado: 18 de julio de 2017 ISSN: 0122-1213 (Impreso) ISSN: 2389-993X (En línea) Doi: 10.25100/prts.v\%vi\%i.5842 Prospectiva. Revista de Trabajo Social e intervención social No. 24, julio-diciembre 2017: pp. 273-301 
Palabras clave: Representaciones sociales (RS); Sustancias psicoactivas (SPA); Jóvenes universitarios; Género; Etnia; Raza.

\begin{abstract}
The article is the product of a research on the trends of consumption and social representations (RS) regarding Psychoactive Substances (SPA) by students from the Northern Cauca (NC) Universidad del Valle, Colombia. The research was conducted with 298 students - women and men. A survey allowed to characterize the consumption of SPA in the university campus. The qualitative tools allowed to capture perceptions and images regarding the consumption of SPA. Although it is true that this group of students do not represent all the young people of the $\mathrm{NC}$, the findings gave interesting clues to understand the consumption of SPA from the social representations built from their status as male, female, afro-descendant or indigenous, projecting in the differential discourses captured throughout the research. Looks of great utility to propose to the future differentiated strategies of intervention that allow a real inclusion in the processes of prevention and mitigation of the consumption.
\end{abstract}

Keywords: Social representations; Psychoactive substances (SPA); University Students; Gender; Ethnicity; Race.

Sumario: 1. Introducción. 2. Apuntes metodológicos. 3. Hallazgos. 4. Discusión. 5. Conclusiones. 6. Referencias bibliográficas

\title{
1. Introducción
}

El proyecto de investigación fue liderado por el programa académico de Trabajo Social de la sede NC con el interés de articular a esta sede regional de la Universidad del Valle a los "Comités territoriales de reducción del consumo de drogas", propuesta del Gobierno nacional para orientar, coordinar, promover y evaluar programas o proyectos de reducción del consumo de SPA y problemas conexos a la entidad territorial. En su 
momento, el interés se suscitó por los resultados de una investigación ${ }^{2}$ que concluyó que el consumo de heroína es un grave problema de salud pública en Santander de Quilichao, municipio donde se encuentra ubicada la sede regional de la Universidad.

Hablar de RS en una comunidad determinada, obliga a dirigir la mirada a su entorno, a los mecanismos del contexto, a sus condiciones culturales, etc. Es un proceso de retroalimentación constante entre el sujeto y la sociedad a la cual pertenece. Según Durkheim (2000) la sociedad conserva su unidad gracias a la existencia de una conciencia colectiva, la cual va más allá de lo individual; por tanto, cualquier fenómeno social se podría entender siempre y cuando se comprendan las dinámicas del entramado de relaciones sociales. En este orden de ideas, la investigación cobró relevancia porque se trató en concreto de obtener información discriminada por sexo para abordar el tema de manera distinta al ya acostumbrando enfoque "neutral" y epidemiológico de los estudios tradicionales sobre SPA, para entrar a explorar las voces de hombres y mujeres, sus percepciones, opiniones e imágenes frente al uso de éstas y apreciar cuán vinculadas están dichas representaciones con las marcas de género y étnico-raciales.

Teniendo en cuenta la multiculturalidad ${ }^{4}$ del $\mathrm{NC}$, el estudio se caracterizó por incorporar un modelo teórico que se distanciaba de aquellos que asumen las categorías de análisis como homogéneas y aisladas. Se acudió al "paradigma de la interseccionalidad" de Crenshaw (1995), para comprender el "sistema complejo de múltiples y simultáneas estructuras de opresión en el cual la discriminación por razones de sexo, raza/etnicidad, edad, preferencia sexual, y otros factores, entre los que se incluye la

2 "Evaluación rápida de la situación de consumo de heroína en el municipio de Santander de Quilichao, Cauca" (2009). Investigación requerida por el municipio al Ministerio de Protección Social y ejecutada por la Oficina de las Naciones Unidas contra la Droga y el Delito (UNODC), en alianza con la Universidad Nacional de Colombia y la Pontificia Universidad Javeriana.

${ }^{3}$ En el estado del arte de la investigación se referenciaron estudios internacionales y nacionales que se concentraron en conocer el tipo de SPA que suelen consumirse, la frecuencia, y otros aspectos que proyectaron una mirada netamente "epidemiológica" y donde se asumieron las SPA como una problemática que hay que diagnosticar e intervenir.

${ }^{4}$ Según proyecciones del DANE (2012), la región del Norte del Cauca tiene una población aproximada de 400 mil habitantes de los cuales el $60 \%$ es afrodescendiente, el $20 \%$ es indígena, distribuida en 21 cabildos y el $20 \%$ es mestiza.

Prospectiva. Revista de Trabajo Social e intervención social No. 24, julio-diciembre 2017: pp. 273-301 
pobreza, interactúan, generando un contínuum que comprende diversas manifestaciones y gradaciones de violencia" (Crenshaw, 1995:359). Lo anterior, articulado a otras teorías contemporáneas de género brindó interesantes aportes a la producción de un conocimiento situado en el contexto norte caucano.

\section{Apuntes metodológicos}

El estudio de carácter exploratorio-descriptivo cubrió tres momentos: el despliegue de lo cuantitativo, lo cualitativo y el análisis de resultados. Inició con una encuesta (de 23 preguntas) aplicada a una muestra representativa de 180 estudiantes de la sede $\mathrm{NC}$, escogidos con el único criterio de estar matriculados ese semestre en alguno de los programas académicos. Dada la naturaleza del tema y la estigmatización que existe al respecto, las personas que participaron en esta fase lo hicieron de forma voluntaria. Dicha encuesta, además de ofrecer una breve caracterización de la muestra, se construyó sobre tres categorías analíticas: SPA, consumo y entorno social. Las dos primeras categorías buscaron evidenciar cómo se comportaba el consumo de SPA entre el estudiantado de la sede regional y la tercera, explorar superficialmente de qué manera las características de su entorno social incidían en las tendencias de consumo. Una vez obtenidos los resultados de la encuesta, se hizo necesario profundizar en temas claves ligados al contexto, aportándole al estudio un enfoque diferencial que incluyó las categorías de género y lo étnico racial. Para ello se hicieron diez entrevistas semiestructuradas y se organizaron tres grupos focales de a 36 estudiantes cada uno, que hubiesen participado en la encuesta y que se auto reconocieran en algún grupo étnico y de género. El diálogo entre lo cuantitativo y lo cualitativo, propio de un estudio mixto, permitió evidenciar que no era suficiente identificar tendencias de consumo, exigiendo la exploración de las RS que desde el enfoque diferencial (género y étnico) se evidenciaron en los estudiantes. Otro elemento metodológico relevante fue que dichas categorías analíticas del estudio cuantitativo se vieron reflejadas en las dimensiones del análisis cualitativo, a las que se les sumaron en este segundo momento la categoría étnico racial como determinante de 
las RS. El análisis de los resultados ofrecidos por la encuesta y utilizados posteriormente para formular las entrevistas semiestructuradas y las guías aplicadas en los grupos focales, se combinaron finalmente para comprobar la idea central: la influencia que las marcas de género y étnico raciales tenían sobre lo que este grupo de estudiantes pensaba sobre el consumo de SPA en un contexto particular.

\section{Hallazgos}

La encuesta aplicada a estudiantes de la Universidad del Valle sede $\mathrm{NC}$, arrojó que $31 \%$ de la población no ha consumido ningún tipo de SPA. Quienes sí lo hacen, suelen consumir SPA legales como alcohol y tabaco. Las mujeres parecen fumar más que los hombres $(2,3 \%$ y $1,1 \%$ respectivamente), al igual que consumir bebidas alcohólicas, pues el 64,4\% de las mujeres encuestadas reportaron su ingesta, frente al $46 \%$ de los hombres. El 1,1\% de los hombres reportó consumir cannabis o marihuana, ninguna mujer reportó su consumo. La combinación de ingesta de tabaco y alcohol es del $21,1 \%$ de los hombres, frente al 11,1\% de las mujeres. Los datos se diferencian sustancialmente en las combinaciones de tabaco, alcohol y marihuana, pues los hombres parecen consumir más estos tres tipos de SPA $(11,1 \%)$ respecto a las mujeres $(3,3 \%)$. Igual sucedió con la combinación de tabaco, alcohol, cocaína, marihuana e inhalantes pues, en sumatoria, el 8\% de los hombres las han consumido, contrariamente a las mujeres que no lo hacen.

En los discursos de los (las) estudiantes procedentes de comunidades afro, se asoció la pertenencia a un estatus alto si en las celebraciones se ingieren bebidas alcohólicas como el whisky y el vodka, mientras que el ron, el aguardiente, las bebidas tradicionales o artesanales como el "arrechón" o el "tumbacatre" se asocian a estatus medios o bajos respectivamente. Así lo expresó en sus palabras una de las entrevistadas: (...) el que tome más aguardiente es más macho, o el que tome whisky, dicen que ese negro es fino, que tiene boca fina (...) (Mujer afro descendiente, "comunicación personal"). 
Las discotecas y las casas usadas para festejos y reuniones sociales son los espacios predilectos de los (as) estudiantes para consumir alcohol y tabaco. Así lo reportó el $30 \%$ de la población, mientras que otros entornos como universidad o espacios públicos no superaron el 1.7\% de las respuestas. Los (as) entrevistados (as) afrodescendientes e indígenas coincidieron en que en sus comunidades se presenta más el consumo de drogas legales que de ilegales, por la facilidad para acceder a ellas, o por la influencia de agentes socializadores como la familia, las amistades o las mismas políticas gubernamentales. Así lo expresaron algunos (as) informantes:

(...) cuando nuestros padres se sientan a tomar con los amigos, se amanecen y todo eso. Hay niños y los niños también van viendo y van aceptando como que eso es algo normal y también empieza a ser parte como de la vida cotidiana de ellos (...) (Mujer, grupo focal, "comunicación personal")

Para los (las) estudiantes indígenas, el consumo de alcohol y otras SPA también se asocia a una condición ancestral que involucra la identidad y las tradiciones. Hacen una diferenciación más marcada entre el alcohol común (aguardiente, por ejemplo) y el alcohol tradicional, categoría en la que se encuentran variaciones como la chicha y el guarapo, específicamente. El anclaje cultural se refleja en discursos como:

Se consume la coca, la hoja de la coca para la medicina tradicional, eh, dentro de los procesos, rituales y todo el significado simbólico y cultural que tiene la coca, o sea, la coca como una planta medicinal, una planta representativa para la comunidad indígena (...) la marihuana también para procedimientos de plantas medicinales, la amapola que también sale una sustancia que no recuerdo (...) y aunque es una bebida alcohólica la chicha, pues que es algo histórico y ancestral (Mujer indígena, "comunicación personal")

Algunas líneas teóricas asumen que el consumo de las SPA es un hecho social que está atravesado por RS, a su vez enmarcadas en límites definidos a través de la norma y por tanto de lo que es vetado o no en un contexto específico. En este sentido, los relatos dieron cuenta de un entorno norte 
caucano en donde predominan el reproche y discriminación social hacia quien consuma SPA consideradas prohibidas o ilegales. Así lo expresaron:

Está muy mal visto que alguna persona consuma algún vicio y esa persona ya está mal tildada y nunca... pues va a conseguir trabajo (Hombre afrodescendiente, "comunicación personal")

(...) por ejemplo uno ve a cualquier muchacho por ahi y dice: ;Ah! Ese es marihuanero, o éste es al que le gusta meter vicio por allá, pero cuando la gente está junto a ellos no les dicen nada, entonces es como eso, se señala pero no de frente y tampoco se presentan soluciones, solamente se juzga y ya (Hombre indígena, "comunicación personal")

En los hallazgos de esta investigación la RS no deseable para los (las) entrevistados, fue la connotación de "vicioso":

Señalamiento si hay, claro, porque por lo general a las personas que consumen cualquier tipo de sustancias, más que todo ilegales, se le van a denominar "viciosos". Entonces en la comunidad se dan señalamientos y se da el prejuicio, por lo menos en las comunidades consideran que las personas negras que consumen son ladronas, asesinas, atracadoras, porque dicen: "como es negro es vicioso y ese negro es un malandro", entonces también se da la discriminación y es señalamiento por su cultura y por la sustancia que él consuma (Mujer afro descendiente, "comunicación personal")

Los y las informantes proyectaron en sus discursos un escenario social donde prima la "escala de lo moral", determinante para el veto hacia todo lo relacionado con el consumo de SPA. Para la mayoría, el factor frecuencia representa la "delgada línea" que separa lo aceptable de lo inaceptable socialmente. Esa palabra es la que en las RS de la comunidad permite identificar "al vicioso" de la persona que consume para celebrar o departir socialmente. Las SPA legales no son consideradas por las personas entrevistadas como algo totalmente negativo: esta connotación se empieza a asumir cuando el consumo se torna excesivo y aparece la adicción, la cual responde (según los hallazgos de las entrevistas) a una decisión personal. Otra coincidencia entre los (as) entrevistados (as) afrodescendientes e indígenas es que el consumo de SPA (principalmente alcohol y tabaco)

Prospectiva. Revista de Trabajo Social e intervención social No. 24, julio-diciembre 2017: pp. 273-301 
se caracterizó como un "acto social", una actividad que remite a espacios de diversión grupal como reuniones familiares, fiestas y discotecas. Así lo expresó una estudiante:

Cuando usted consume solo en este caso alcohol, pues sencillamente no hay esa red de amigos que lo motiven, ;hay que chimbo uno estar, digo, que horrible uno estar tomando solo!, en cambio cuando usted tiene a los amigos, el ambiente, se siente chévere, se siente querido, se siente apoyado, pero hacerlo solo es una cuestión de desilusión, o sea porque ahi se nota de que no tenés un amigo con quién compartir (Mujer afrodescendiente, "comunicación personal")

Las personas entrevistadas reportaron haber consumido por primera vez algún tipo de SPA entre los 11 y 16 años (78\% entre hombres y mujeres). Las razones para iniciar el consumo se pueden observar en la figura no. 1.

Figura 1. Razones para consumir SPA por primera vez.

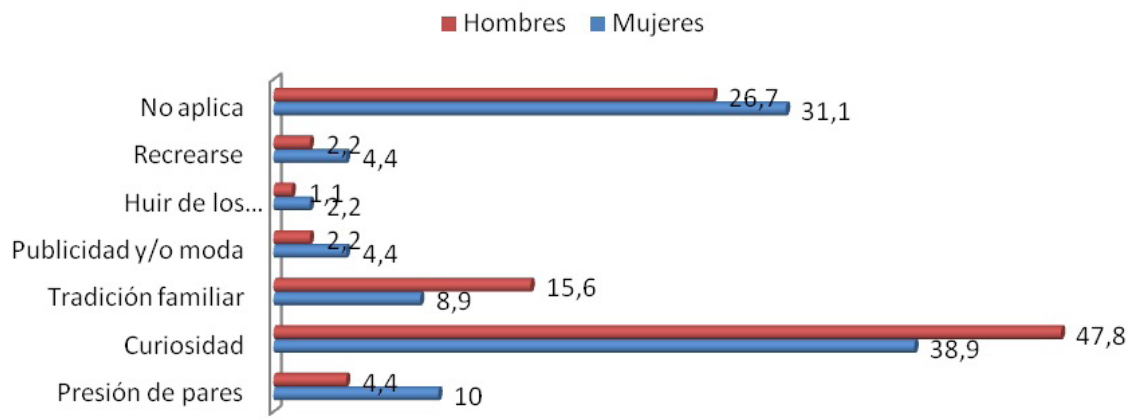

Fuente. Elaboración propia.

Comentaron que sus expectativas cuando consumían alcohol, principalmente era desinhibirse, y "alargar" momentos de felicidad. Según el $90 \%$ de los datos obtenidos, hay un reconocimiento de la posibilidad de riesgo que ofrecen las SPA para la salud mental, física y social, sin embargo, esto no inhibe el consumo porque prima la idea de placer. Sólo un $10 \%$ restante priorizó la idea de alto riesgo, percepción que ha ocasionado una actitud más precavida en su consumo para este grupo de informantes. 
Lo mencionado se pudo dilucidar en un diálogo que sostuvieron dos estudiantes en uno de los grupos focales:

Mujer: obvio tiene que haber placer, porque si no hubiera placer no sería adictivo, ¿no?, o no gustaría tanto. No sería por decirlo así: "endulzador"; y riesgo, obvio, ya cuando estás consumiendo y consumiendo, llegas a un extremo en el que te estás dañando o donde estás dañando a otras personas, a eso se le podría decir que está lo dulce y la parte donde ya estás empezando a correr riesgo, uno mismo y los demás (Grupo focal mixto).

Hombre: cuando tú dices placer, en esos momentos estás es en riesgo, ¿por qué? Porque si yo estoy consumiendo alcohol y pues quiero emborracharme, pero en ese momento en que me metí la primera copa tengo ya un avance del placer, en ese momento empieza el riesgo, porque a la segunda ya no vas a poder parar, y el riesgo que se está corriendo es no poder parar, entonces yo pienso que eso es parejo (Grupo focal mixto)

Las y los estudiantes de la sede NC elegidos para la recolección de información expresaron en su mayoría ideas y concepciones en cuanto al género marcadas por diferencias al construirse como hombres y mujeres, así: “(...) a nosotros los hombres nos forman para ser fuertes, para ser más resistentes a determinados tipos de trabajos y las mujeres son un poco más sensibles" (Hombre afrodescendiente, "comunicación personal” 01, octubre, 2013)

Estos estereotipos de género se visualizaron en las representaciones sociales que tenía la población respecto al consumo de SPA. Así lo expresaron:

"Creo que uno como hombre tiene más libertad que la mujer, pues a la mujer se le estigmatiza mucho porque uno ve una mujer tomando por ahi o fumándose un cigarrillo y es como ver algo raro ¿no?, es lo que uno cree (Hombre indígena, "comunicación personal")

“... a la mujer la ven consumiendo alcohol, y jhay Dios mío santo un problema!; a la mujer la ven consumiendo de pronto una cerveza "ay ve ¿y ésta?"”, "¿con esa cerveza qué es qué piensa””; o la ven metiéndose un cachito de marihuana o algo así, pues peor. Entonces, en el hombre no es tan marcado (Mujer afrodescendiente, "comunicación personal") 
La mayoría de estudiantes entrevistados (as) creen que en sus contextos locales se señala de manera decidida a las mujeres que consumen algún tipo de SPA, y valoran negativamente dicho acto. En la figura 2, se pueden apreciar las respuestas de hombres y mujeres frente a la pregunta: ¿quién considera que tiene mayor permisividad social para consumir SPA?

\section{Figura 2.Consumo y aceptación social según género.}

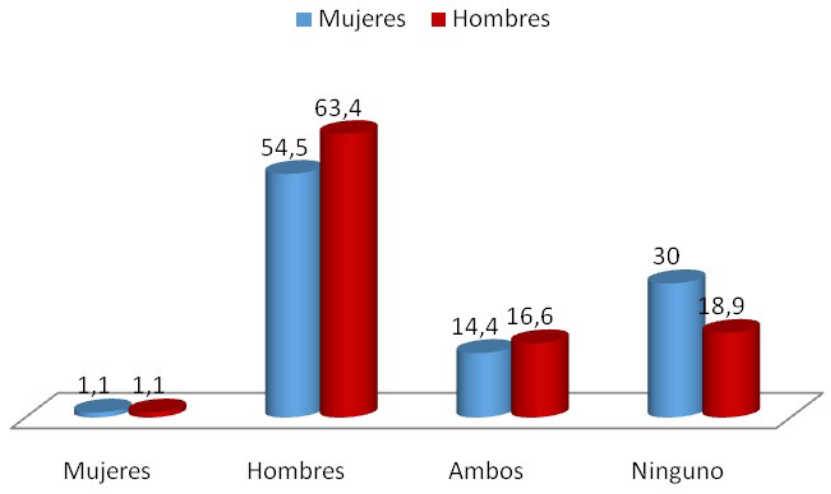

Fuente. Elaboración propia.

Algunos/as admitieron compartir esta creencia, negando la posibilidad de que las mujeres se "igualen" a los hombres en el acto de consumir SPA:

... yo por lo menos no concibo o me parece desagradable ver a una mujer ebria, o sea, ver una mujer listo, una mujer que se tome unos tragos, pero una mujer totalmente ebria, ¿cómo puede llegar a quedar uno? Que se quede dormida en tal sitio, dé espectáculos, para mí eso me parece repugnante (Hombre indígena, "comunicación personal")

En esta opinión se puede apreciar que no solo es inadmisible ver a una mujer bajo los efectos de algún tipo de droga, sino que le resulta preocupante cómo sería interpretada su imagen en el caso de que lo acompañe una mujer ebria, demostrando así una superioridad masculina que debe ser preservada no solo por los actos individuales sino por los actos de la mujer-objeto que acompañe o "adorne" la escena. 
Algunas de las perspectivas surgidas en las ciencias sociales para comprender modos de RS, contemplan que las asociaciones que suelen hacerse desde lugares comunes frente a las identidades étnicas raciales y el consumo de SPA obedecen a estereotipos, a través de los cuales se juzgan las conductas actuales y futuras de individuos pertenecientes a comunidades afro o indígenas. De acuerdo a estos hallazgos se encontró que una persona mestiza o blanca que consuma variedad de SPA va a estar menos estigmatizada que quien lo haga desde una identificación afro o indígena. Lo anterior se proyecta en el siguiente argumento:

"...porque si usted es blanco consumidor, le dicen "usted es hijo de papi y mami", si usted es negro consumidor, le dicen "usted es el negro marihuanero, ladrón vicioso", si usted es indio, le dicen "este indio hijueputa vicioso" (Mujer afrodescendiente)

Estereotipos asociados a la delincuencia y al consumo de SPA conforman las imágenes mentales que en la vida cotidiana se producen en detrimento de las personas. Otra perspectiva usada desde la representación del anterior estudiante, tiene que ver con los procesos de recepción y asimilación de prácticas externas en las dinámicas comunitarias y/o de pertenencia étnica. De esta manera, se percibió una asociación de la comercialización de estupefacientes como acciones propias de la acumulación de capitales que supone el modelo económico actual. Así, su difusión propone situaciones donde poblaciones con pertenencias étnicas incorporan el consumo de SPA.

si usted ve a un indígena consumir yerba, cocaína o una de esas, dicen eso hace parte de ellos, es que ellos son así, eso es normal; y cuando vos ves a un afro digamos consumir alcohol y todo eso también se dice es que ellos ya son así, desde pequeños vienen consumiendo, eso se ve normal; sin embargo, cuando se observa el consumo, digamos en una persona blanca, aunque blanco no existe, se asocia a otros términos, porque se dice no, ese muchacho qué será que le falta en la casa, ese muchacho que será qué le pasa, se comienza a dar otra connotación (Mujer afrodescendiente, "comunicación personal") 


\section{Discusión}

\section{“El que más tome, es el que más puede": SPA y status}

Las representaciones sociales ante el consumo de SPA vistas desde una perspectiva de género y étnico racial, supuso para este estudio identificar cómo el alcohol y el tabaco simbolizan (para estudiantes afrodescendientes particularmente), objetos que brindan a los hombres la posibilidad de afianzar o construir su masculinidad a partir de su consumo. Así mismo, se logró identificar la relación que tiene el consumo de estas sustancias legales con dos elementos claves de las RS como son el rol social, y el estatus. Parsons (1999) define el primer concepto como lo que se espera de un individuo y, el segundo, como la posición social que ocupa en dicha estructura. En este sentido, para ubicar dichos imaginarios acerca de las SPA en un contexto étnico-racial, se tiene que asociar "qué se consume" con "quienes lo consumen". El acceso a determinado tipo de alcohol o cigarrillo (para este caso) estaría supeditado a la capacidad adquisitiva del consumidor, por tanto, en eventos sociales como celebraciones, fiestas, discotecas, etc., el (la) consumidor (a) mostraría su estatus a partir del tipo de alcohol o cigarrillo que esté comprando. Estaría tratando de establecer o reivindicar su rol social por medio del consumo. Goffman (1963) en su Teoría de la Acción Social plantea, entre otras cosas, que cuando "las personas están la una ante la otra pueden funcionar no sólo como instrumentos físicos, sino también como instrumentos de comunicación" (p. 27) por tanto recurren a una fachada, a un despliegue dramatúrgico de sí mismo con la intención de transmitir atributos positivos que generen aceptación en otros y/o el establecimiento de un estatus y rol social. Este último sirve para promulgar los derechos y deberes atribuidos a un estatus dado, implicando que el "actor" o sujeto social desempeñe uno o más papeles, en los cuales deberá, de manera voluntaria o involuntaria impresionar a los otros. Para lograrlo, el sujeto utiliza lo que el autor denomina "un vehículo de signos" que son fuentes de información accesible y generalmente visible que se usa para transmitir una imagen que impresione $y$, por tanto, obtener una respuesta determinada de los demás. 
Para el caso de esta investigación, específicamente en los datos de los (as) estudiantes provenientes de comunidades afrodescendientes, un "vehículo de signos" utilizado para expresar estatus, rol social y/o poder, es el tipo de alcohol o de cigarrillo que se consume. En palabras usadas en el teatro sería una suerte de "decorado", es decir, en un objeto que fortalece el despliegue dramatúrgico del actor social, ya que este tiene una imagen que mostrar, ya sea para ganar respeto o simplemente para impresionar, logrando una respuesta determinada por parte de los otros, que en este caso generalmente está referido a la admiración si se consumen licores asociados a "estratos altos" y a estar rodeado de mujeres hermosas que "aporten belleza" (alusivo a la cosificación de la mujer) a la escena que el hombre esté representando en una discoteca o en una reunión social.

\section{"Si es legal no es tan mala para la salud"}

Los hallazgos ratificaron que la RS que hay del límite entre lo legal o lo ilegal de las SPA en una sociedad o, particularmente, desde las políticas de un Estado, es un fuerte condicionante para estimular o no estimular su consumo. En la sociedad moderna, los medios de comunicación, las tecnologías de la información hacen posible la "difusión de imágenes, nociones y lenguajes que la ciencia inventa incesantemente y que acaban integrándose al bagaje intelectual de los hombres de la calle" (Hewstone y Moscovici, 1986, p. 684). Dichas imágenes y lenguajes son identificables en Colombia a través de la publicidad reglamentada ${ }^{5}$ la cual proyecta el aval a ciertas SPA que son consideradas legales. Las legislaciones expresan el mecanismo utilizado por el Estado para socializar una RS entre lo que es prohibido o lo que no lo es; podría pensarse que para el caso estudiado se da un discurso ambiguo, porque si bien hay una legislación que regula

${ }^{5}$ En Colombia está vigente un marco legislativo que proviene de los años ochenta en el que se pretende controlar el tabaquismo y el consumo de alcohol. Cabe anotar que dichos decretos o resoluciones no catalogan estas dos SPA como ilegales, son netamente disposiciones para controlar su consumo. Entre las más sobresalientes, relacionadas con el punto que se está tocando se encuentran: Decreto 3430 noviembre de 1982, la Resolución 4225 mayo de 1992, Acuerdo 3 de 1993, la Ley 124 de 1994. Todas referidas a la publicidad de SPA en los medios masivos de comunicación. http:/www.allforweb.com/fuentes.htm y http://www.alcaldiabogota.gov.co/sisjur/normas/Norma1.jsp?i=291 [Consulta: septiembre de 2014]

Prospectiva. Revista de Trabajo Social e intervención social No. 24, julio-diciembre 2017: pp. 273-301 
y una publicidad que "advierte", la permisividad sigue presente, al menos en lo referente al alcohol y al tabaco, conllevando a ser consumidas sin mayores prevenciones. Cuando se habla de SPA se debe ubicar el lugar que éstas ocupan en un imaginario social según la coyuntura histórica, social, política. Es bien sabido que las drogas se han usado desde las primeras civilizaciones, en su mayoría con fines espirituales, metafísicos o para conservar un orden social. Sin embargo, con la llegada del capitalismo y las sociedades de consumo se pasó a un uso indiscriminado, lo que algunos autores llaman toxico dependencia; la cual está asociada más a la recreación u ocio, desarticulándose de búsquedas religiosas o metafísicas de los sujetos (Mazzoti, 2006).

Los nuevos usos de las SPA conllevaron a un incremento en su producción y consumo, ante lo cual algunos países transformaron su percepción, surgiendo (alrededor de los años 1920) una categorización de lo legal y lo ilegal, que se tradujo en persecuciones ${ }^{6}$ a quien estuviera relacionado con ella. La legalidad de las SPA se da porque son producidas por industrias formalmente constituidas que pagan impuestos y que adelantan sus procesos desde una lógica empresarial, por tanto su enclave en la estructura social resulta más apto y, por tanto, más aceptado socialmente. Por ejemplo, la DEA (Drug Enforcement Administration) tiene una lista donde se catalogan los diferentes tipos de SPA en rangos de I a IV, las sustancias tipo I son prohibidas y penalizadas por la mayoría de países occidentales. Sustancias como el tabaco, el cacao, la cafeína y el alcohol no aparecen en las listas ${ }^{7}$, por ello, no son catalogadas como drogas y, por tanto, no perseguidas según las instancias internacionales. Es en este

${ }^{6}$ En Estados Unidos por ejemplo, entre 1920 y 1932 se instauró la "ley seca" con la cual se buscaba prohibir, fabricar y vender bebidas alcohólicas. Dicha prohibición dio origen a uno de los periodos de violencia contra y entre organizaciones criminales más importantes del siglo XX en el continente americano. Este tipo de acciones se retomaron en Colombia, pues durante los años noventa se instaló un marco legal y una infraestructura dirigida a perseguir a los productores de drogas denominadas ilegales. El "Plan Colombia" es un gran ejemplo de ello.

${ }^{7}$ Este argumento resulta contradictorio con la definición que hace la OMS, ya que los síntomas también pueden producirse por drogas denominadas por la DEA como legales. La OMS asume que una "droga es toda sustancia que introducida en el organismo por cualquier vía de administración, produce una alteración de algún modo, del natural funcionamiento del sistema nervioso central del individuo y es, además susceptible de crear dependencia, Prospectiva. Revista de Trabajo Social e intervención social No. 24, julio-diciembre 2017: pp. 273-301 
punto donde se ubicó la RS de los /las informantes respecto a la influencia que tiene la permisividad social del alcohol y el tabaco y la naturalización de su consumo.

Las RS pueden tener un elemento coercitivo, en la medida en que utilizan dispositivos (Foucault citado en Agamben, 2011) para construir y perpetuarse, enmarcándose en una relación de poder. En este caso el dispositivo sería el conjunto de legislaciones, el marco moral y filosófico desde el cual se planta el Estado Colombiano para categorizar las SPA entre legales o ilegales. Un dispositivo que si bien refleja algunos vetos, no plantea una prohibición explícita de sustancias como el alcohol y el tabaco. Aunque los sujetos, al momento de asumir una representación social tienen la libertad subjetiva de apropiación y de "crear" conocimiento o reflexión, es un elemento débil para autores como Foucault (2005), ya que para él, la subjetivación es tan pequeña respecto a los dispositivos sociales que no alcanzarían a hacer una modificación total de los mismos, pero sí podrían convertirse eventualmente en una "fisura" estratégica para modificar las relaciones de poder, las cuales si pueden ser cambiantes.

Los dispositivos y las fuerzas de poder que están presentes en las RS que tuvo la población entrevistada respecto al alcohol y el tabaco, se enmarcan en lo que Foucault (2005) llama el "diagrama" definido como una multiplicidad espacio-temporal donde actúan dispositivos concretos que se integran en sustancias cualificadas a partir de funciones, ya sea de control, educación, producción, higiene, etc. El diagrama hace uso de las tecnologías para materializarse. En este sentido, asociándolo con el caso colombiano, se puede observar la instalación de un diagrama donde claramente existen dispositivos concretos como la cárcel, las políticas de prevención de SPA, los marcos jurídicos, los planes educativos que deben involucrar la prevención del consumo, etc., intentando perpetuar imaginarios en los sujetos que les induzcan a pensar y actuar de determinada manera hacia las SPA ilegales. Así mismo dispone de una serie de mecanismos y dispositivos para generar representaciones sociales que avalen las SPA legales. Es de resaltar que algunos (as) estudiantes expresaron esas RS

ya sea psicológica, física o ambas". http://www.conadic.salud.gob.mx/pdfs/nueva_vida/ prevad_cap1.pdf [Consulta: octubre de 2014]

Prospectiva. Revista de Trabajo Social e intervención social No. 24, julio-diciembre 2017: pp. 273-301 
cuando hicieron alusión a las estructuras y actores que tienen intereses económicos en el mercado legal de las SPA. Lo que nos llevó a pensar como investigadoras, que las (los) estudiantes utilizaban su formación universitaria para construir representaciones sociales desde perspectivas críticas o reflexivas, potencial fisura (Foucault, 2005) que podría estar explicando e influyendo a mediano o largo plazo las ideas que se tienen acerca de las SPA en el Norte del Cauca.

\section{SPA y prácticas ancestrales}

Según la Antropología, los ritos, valores, creencias, ideologías, etc., insertadas en una cultura se convierten en hilos conductores de un pensamiento construido colectivamente a partir de su historia y sus interacciones cotidianas (Clifford citado por Cañedo, 1999). Al respecto, las representaciones sociales que poseen estudiantes procedentes de comunidades indígenas sobre SPA como la $\operatorname{coca}^{8}$, la marihuana, la chicha (a base de maíz) parte del lugar adjudicado en sus rituales, valores o creencias. De ahí la tendencia en esta población a naturalizar su consumo pero a su vez, a vetar o despreciar aquellas sustancias como la heroína, la cocaína, etc., que son elaboradas y consumidas por fuera de una "cosmovisión" ancestral.

El consumo de SPAha hecho parte de la historia de la humanidad, llevando a quienes las consumen a modificar su estado de consciencia habitual. En algunos casos, particularmente en las sociedades occidentales tienen un uso "recreativo", pues desinhiben la conducta, relajan y generalmente

\footnotetext{
${ }^{8}$ Es una planta usada ancestralmente por comunidades indígenas latinoamericanas, particularmente andinas. La cultura Inca fue gran productora de la hoja de coca; en un principio fue prohibida por los españoles porque relacionaron su consumo con prácticas religiosas indígenas. Sin embargo, con el paso del tiempo y de haber identificado la particular propiedad de la coca que hacía a los indígenas trabajar más con menos alimentación, decidieron tolerar su cultivo, siempre y cuando no se asociara el consumo con cualquier matiz religioso o espiritual. Incluso, se naturaliza su uso a partir de una ordenanza del virrey en 1573, quien considera que el consumo y tráfico de estas hojas "es necesario para el bienestar de los indios" (Escohotado, 1998, p. 277).

${ }^{9}$ Para el análisis se hizo acopio de lo planteado por Escohotado (1998) sobre el uso de las SPA como "válvulas de escape" con fines recreativos, pues la población encuestada y entrevistada las asoció con dicho fin. Además, no se logró identificar tendencias adictivas de SPA en la población universitaria, de manera que no consideramos pertinente asumir la Prospectiva. Revista de Trabajo Social e intervención social No. 24, julio-diciembre 2017: pp. 273-301
} 
se les asocia con el placer o el goce. Mientras que en otras sociedades, las llamadas tradicionales, poseen una connotación más profunda, porque suelen utilizarse para modificar el estado de conciencia en el marco de experiencias psico-físicas con fines espirituales (Escohotado, 1998).

Ser indígena en el NC implicaría -así se consuma o no- reconocer en la hoja de coca y la chicha, un elemento identitario, una representación social donde estos tipos de SPA no tienen un veto social y su uso no infringe normas o reglas pre establecidas. Estarían (según se visualizó en los discursos del estudiantado) reforzando un estereotipo ${ }^{10}$. Gracias al estereotipo y a las expectativas de rol que éste incluye, que la normalización del consumo de dichas sustancias constituye un trasfondo ideológico. En otras palabras, la relación: comunidad indígena / naturalización de la coca, ratifica la procedencia e identidad cultural de los mismos, mientras que se estigmatizan aquellas que son elaboradas sintéticamente o se usan con otros fines, pues se asumen como prácticas "occidentalizadas" que pueden debilitar la "propia identidad de los pueblos indigenas y los amplios aspectos de diversidad cultural que poseen para la formación, el conocimiento y el consumo de plantas sagradas enfocadas a la curación, comunicación ancestral y demás rituales patrimoniales ejercidos con base en su cosmovisión y origen del mundo” (Mendoza, Romero, Mendoza, Posada, 2015,p. 7).

\section{Relación producción - naturalización del consumo}

Para las (los) estudiantes que se auto identificaron como indígenas, el consumo de marihuana se ha intensificado en los últimos años en sus territorios, según ellos y ellas, porque al sembrarla, el precio baja y por tanto resulta más accesible para la gente. Aparentemente estas prácticas han llevado a la comunidad indígena del NC a dejar de estigmatizar al consumidor paulatinamente.

línea de otros estudios donde se plantea que la inclinación de la sociedad occidental es usar y abusar de las SPA para ahuyentar el dolor o el displacer, lo cual generalmente conlleva a diversas patologías individuales y sociales (Medina, Nateria, Borja, 2001)

10 "Categorías cognitivas que las personas emplean para codificar, almacenar y recuperar la información proveniente de sus interacciones con otros seres humanos, y como tales podrían concebirse como parte del componente cognitivo de las actitudes, también involucran algunas dimensiones afectivas" (Hamilton, 1985, p. 14).

Prospectiva. Revista de Trabajo Social e intervención social No. 24, julio-diciembre 2017: pp. 273-301 
Los cultivos ilícitos en Colombia surgieron, entre otras cosas, por su cercanía con otros países andinos como Perú, Ecuador y Bolivia: Estos últimos en los años setenta fueron los mayores productores de coca de la región. Es por esta época, que narcotraficantes colombianos empezaron a traer de Ecuador coca de forma ilícita. Posteriormente, se empieza a sembrar en el país, generando un entramado de relaciones sociales alrededor de dicha actividad. Es en la misma década, en que en la Sierra Nevada de Santa Marta y en la Serranía de Perijá se empezó a sembrar marihuana, cifras que ascendieron a 30.000 hectáreas (Romero y Silva 2009). En respuesta, el Consejo Nacional de Estupefacientes aunó intenciones con el gobierno norteamericano (años ochenta) para iniciar planes de erradicación de cultivos. Estas estrategias se trataron de fortalecer a partir de la implementación del "Plan Colombia""l. Posteriormente, en el año 2014 la prensa $^{12}$ nacional denunció un crecimiento del número de consumidores y por tanto de las hectáreas para su siembra. En dicho artículo, el Observatorio de drogas de Colombia reconoció que "el 87 \% de los consumidores de drogas ilícitas son consumidores de marihuana". Los cultivos están ubicados principalmente en el Cauca, Magdalena y Tolima. En el Cauca se concentra en el nororiente, en municipios como Toribio, Caloto, Corinto, Miranda, en donde hay censadas oficialmente 65 hectáreas sembradas con marihuana. Desde este punto de vista, podría interpretarse que el fenómeno de la siembra de cannabis en el Cauca por parte de campesinos (aparentemente/principalmente indígenas) ha

${ }^{11}$ En el marco del gobierno del ex presidente Andrés Pastrana (1998-2002) se adelantó un proceso de paz con los grupos guerrilleros beligerantes. Dentro de la agenda y con influencia del gobierno de los Estados Unidos, se tocó el tema de erradicación de cultivos ilícitos y prevención del narcotráfico, porque para esa época ya se habían identificado las relaciones entre guerrilla, cultivos y tráfico de drogas. Como resultado de dicha agenda, aparece, y con respaldo del Estado Americano, el Plan Colombia que fue: "Una estrategia del Estado complementaria al Plan Nacional de Desarrollo, su objetivo es conseguir la paz mediante la negociación política con los actores armados" (Departamento Nacional de Planeación, 1998, p. 14). El plan Colombia buscó “desnarcotizar" el conflicto social y armado colombiano desarticulando la producción y comercialización de narcóticos. (Romero, Silva, 2009)

12 "La nueva guerra marimbera en Colombia" Visto en: http://www.semana.com/ nacion/articulo/marihuana-es-la-sustancia-ilegal-mas-consumida-en-colombia/382247-3 [Consulta: martes, 30 de septiembre de 2014]

Prospectiva. Revista de Trabajo Social e intervención social No. 24, julio-diciembre 2017: pp. 273-301 
incrementado su consumo y su naturalización. Este cultivo parece haberse integrado plenamente a la economía local y está siendo asumida como un elemento de sociabilidad comunitaria. Es común que en ciertas economías domésticas se consuma lo que se produce o lo que se siembra en la zona. A propósito, para autoras como Mazzotti (2006) la visión occidental que considera las drogas como "elementos exógenos y peligrosos" explica sus esfuerzos para combatirla y obstaculizar su integración al entramado social. Ratificando la discusión que obliga a comprender el fenómeno de las drogas en el marco social, político y económico de determinado país.

\section{"La celebración y el alcohol”}

Estudiantes auto identificadas (os) como afrodescendientes e indígenas coincidieron en que el alcohol les da acceso a un estado anímico para disfrutar más de la fiesta, de las reuniones sociales, por lo que su uso se incorporó fácilmente a su cotidianidad. El "estado anímico" referenciado por los estudiantes es lo que autores denominan "estado de embriaguez". Dicho estado ha sido una búsqueda asociada a la condición social humana porque su uso pretende alcanzar efectos catárticos y cambios en los estados de conciencia de las personas; concediéndole a las drogas significancia social y sacramental. Según autores como Escohotado (1998), el estado de embriaguez se referencia desde el siglo I por el teólogo Filón de Alejandría, como un acto de "noble júbilo", pues las personas acostumbraban embriagarse para finalizar las ceremonias religiosas de ofrendas, peticiones y sacrificios.

En el siglo XI se pluralizó el tipo de bebidas alcohólicas: aparecen la cerveza, los vinos añejados conllevando a que su consumo no se asociara ya tanto al ritual religioso sino a eventos profanos, como las fiestas. En términos antropológicos y psicoanalíticos las fiestas cumplen la función de "fortalecer cierto sistema de prohibiciones, proporcionando la válvula de escape para la tensión que son transgresiones periódicas o bien que constituye sencillamente un momento donde se suspende la rutina de la existencia" (Escohotado, 1998, p. 51). Para ello, las sociedades (en sus diagramas de poder) cuentan con dispositivos concretos como los bares, discotecas, etc. Por ser lugares donde el consumo de alcohol se acompaña 
de música, baile y otras formas de expresión humana; son espacios socialmente aceptados en los que los asistentes pueden dar rienda suelta a sus impulsos y pueden liberarse de las tensiones periódicas a las que están expuestos, lo que incluiría llegar a estados de embriaguez. Para este caso, que finalmente concretaría las apreciaciones de los (las) estudiantes, el consumo de alcohol como conducta individual, está determinada por los factores culturales y sociales de su entorno, pues en países como Colombia, donde el alcohol es comercializado libremente, la estructura social, la cultura, las mismas costumbres, los roles sociales, conllevarían a naturalizar su consumo, pues se va asociar permanentemente a alcanzar un estado de euforia o alegría que facilita la desinhibición y la socialización (Escohotado,1998).

Consumir alcohol grupalmente está dando cuenta de una compleja actividad social, pues a la acción individual de ingerirlo le anteceden las construcciones sociales que se han hecho al respecto. Según Mead, desde la lógica del interaccionismo simbólico "el todo social precede a la mente individual lógica y temporalmente" (Mead citado por Ritzer, 2001 p. 253), de manera que la acción de consumir no es producto de un estímulo que ocasione una respuesta automática e irreflexiva, por el contrario, el estímulo (la fiesta, la celebración, la familia/amigos reunidos) se vuelve una ocasión u oportunidad para actuar, más no es en sí misma un mandato o una compulsión. Esto es lo que el autor denominó "acto" es decir, la circunstancia donde entran a jugar varios factores que llevan a los sujetos a concretar o no concretar alguna acción, que para este caso sería la fiesta como acto, y la ingesta de alcohol como acción. Asumir el acto de consumir alcohol como un acto social evidencia la apertura hacia esta sustancia en particular y el lugar que ocupa en los rituales sociales que son significativos para las y los estudiantes, quienes, indiferente a su origen étnico-racial, ven en el alcohol una sustancia que les permite socializar más y conservar ciertas tradiciones y dictámenes culturales. De ahí que su consumo se realice - según los hallazgos de la investigaciónexclusivamente con personas de su entera confianza, como son los amigos y la familia. 


\section{"Señalo pero no excluyo, a menos que..."}

Según la Sociología de la desviación ${ }^{13}$ existe normas asociadas con la moral individual, normas sociales, normas jurídicas y normas penales, cada uno de estos sistemas normativos tendría su respectiva forma de sanción o veto. La desviación consiste en una violación excesiva de la norma que podría poner en peligro el orden social, ya que precisamente la norma, indiferente a su tipología, aparece para salvaguardar a la sociedad de su disolución y prevenir anomias que afecten el tejido social.

Los relatos de las y los entrevistados dan cuenta de un entorno norte caucano en donde predominan el reproche y discriminación social hacia quien consuma SPA prohibidas colectivamente. Aparece entonces como una comunidad con tendencia a la solidaridad mecánica (Durkheim, 2012) relacionada con la variable étnico-racial tenida en cuenta para el presente estudio, ya que en grupos sociales como la comunidad afro y la comunidad indígena predomina la noción de parentesco o consanguinidad, que trae consigo la tendencia a la homogeneidad social en varios niveles, particularmente en las prácticas, la tradición y las costumbres. Poseer ese tipo de solidaridad y de compartir las mencionadas representaciones sociales hacia las SPA muestra un condicionamiento de la norma social, la cual no se hace efectiva con una sanción penal o administrativa, pero sí se hace efectiva con el veto, el reproche, pues el no cumplimiento de la norma estaría poniendo en evidencia la desviación de sujetos que se alejan de los estándares practicados en sus respectivas comunidades. Veto social que según los datos, se proyecta a través de sanciones simbólicas como el "chisme" o la "invisibilización del consumidor" para prevenir la propagación de lo que puede llegarse a considerar un problema.

El rumor, según Weber (1971), posibilita que las ideas de un grupo social emerjan y se intercambien, además de que expresa la escala de valores y la moral desde las cuales se califica las acciones de los otros. Puede interpretarse también como un parámetro de comportamiento o

${ }^{13}$ Este concepto se trae a colación sin ninguna connotación moral, característica que parece serle inherente en el lenguaje cotidiano, por el contrario, se asume desde la mirada de las ciencias sociales donde indica "la falta de conformidad con una serie de normas dadas, que sí son aceptadas por un número "significativo" de personas de una comunidad o sociedad" (Giddens, 2000: 231)

Prospectiva. Revista de Trabajo Social e intervención social No. 24, julio-diciembre 2017: pp. 273-301 
como un indicador de posibles rupturas o conflictos al interior de un grupo social. Desde la psicología social, algunos autores definen el chisme como "una proposición específica para ser creída, que pasa de persona a persona generalmente por vía oral, sin medios de prueba seguros para demostrarla" (Allport \& Postman,1947, p.15), sin embargo, aunque el chisme no siempre se pueda comprobar, según estos autores, al chisme le subyace uno o varios asuntos que son importantes para un colectivo determinado, puesto que estaría reflejando las incertidumbres, miedos o problemas que tienen los sujetos respecto a algún fenómeno, en este caso el consumo de SPA.

A partir de lo anterior se puede comprender por qué en la población investigada consumir drogas hace referencia a una categoría social "indeseable", ante la cual hay que socializar negativamente, aconsejar para que no se llegue nunca a ser un "vicioso". Sumado a esto, para el caso de la comunidad afrodescendiente se evidencia una representación social sustentada en un señalamiento alterno, una doble discriminación, en el sentido en que ya tiene una valoración negativa el consumir drogas, pero al ser consumida por un afrodescendiente da pie para que ese sujeto sea asociado con actividades delictivas.

Ala luz de los planteamientos de Crenshaw (1995) respecto al "paradigma de la interseccionalidad"14 la estructura social puede generar sistemas de discriminación en variados y simultáneos niveles. Aparentemente, para la población afro, el consumo de SPA ilegales significa un potencial peligro para su tejido social, por tanto, suele generar mayor prevención un afrodescendiente que consuma SPA a un indígena que haga lo mismo, en el sentido en que al segundo probablemente se le generen chismes o rumores relacionados con su consumo, pero está atravesado por una identidad cultural, mientras que al primero además de los rumores, también se le genera una discriminación y señalamiento más evidente que por obvias razones puede traerle mayores consecuencias negativas para su vida individual y social. El "veto social" parece privilegiarse en el contexto

${ }^{14}$ Definido como un "sistema complejo de múltiples y simultáneas estructuras de opresión en el cual la discriminación por razones de sexo, raza/etnicidad, edad, preferencia sexual, y otros factores, entre los que se incluye la pobreza, interactúan, generando un contínuum que comprende diversas manifestaciones y gradaciones de violencia" (Crenshaw, 1995, p. 359)

Prospectiva. Revista de Trabajo Social e intervención social No. 24, julio-diciembre 2017: pp. 273-301 
norte caucano, a diferencia de otros municipios y departamentos del país donde históricamente se han dado expresiones de violencia explicitas hacia los consumidores / expendedores de SPA, bajo lo que se conoce como "la limpieza social”. Si bien en municipios del Cauca como Popayán, y para el caso Santander de Quilichao, pudieron presentarse estos casos, según cifras municipales no fueron reconocidos por las autoridades como tales y se les asoció a las acciones de la delincuencia común, de bandas criminales y pandillas. La población entrevistada dio cuenta de comunidades donde parece existir una claridad respecto a la norma jurídica porque conocen las sanciones por consumir SPA ilegales, de ahí que la sanción formal suelan delegarla a las autoridades competentes y a nivel informal utilizan el rumor y el prejuicio para una suerte de "control" social cotidiano.

\section{Articulaciones entre género, etnia y raza}

Los hallazgos al respecto de las representaciones de género evidenciaron rasgos de un pensamiento dicotómico occidental que entiende las realidades sociales en términos de conceptos opuestos (Maffía, 2003), sus modos de concebir el ser hombres y/o mujeres indican desigualdades propias de estructuras sociales y culturales patriarcales que privilegian en sus discursos y prácticas una supremacía masculina en detrimento de lo que se pueda llegar a considerar femenino, por ejemplo, ser "fuerte" sería más valorado que ser "sensible". Los mencionados estereotipos de género son asumidos sin advertir las exclusiones y jerarquizaciones que conllevan. De esta manera, si se requiere calificar de algo racional u objetivo se piensa en hombres, porque las mujeres están bajo estereotipos que las encasillan en calificativos asociados a la emocionalidad o subjetividad. Aunque las estructuras socioculturales poseen un reparto de cualidades diferenciado para hombres y para mujeres desde su infancia, el cumplimiento de aquellos roles no siempre se ajustan a las realidades cotidianas. Tal como lo plantea el pensamiento hegemónico: "dedicarse a la casa" no es tan valorado como ser el hombre proveedor; así, que aunque las mujeres aporten con su salida al mercado laboral, las posiciones y/o estatus otorgados por el género siguen siendo jerarquizadas y por lo tanto ubicándolas en un plano de obediencia. 
Una mirada de género en las creencias y acciones asociadas al consumo de SPA colaboran con interpretaciones que esclarecen por qué el ser portadoras de un género reconocido como femenino es motivo de exclusión de diversos ámbitos de la vida social, incluidos aquellos sobre los cuales se cargan prejuicios y prevenciones sociales como el consumir drogas legales o ilegales, pues se trata de ubicar un sujeto socialmente inferiorizado en un acto que desde diversas percepciones morales es negativamente valorado. Deduciendo que si el hecho de construirse como mujer, dadas las normas e ideologías que priman en la cultura con respecto al género implica desventajas, pues el hecho de identificarse como mujer y consumir algún tipo de SPA implica doble exclusión, ratificando lo propuesto por Crenshaw (1995) en el "paradigma de la interseccionalidad".

Lo anterior proyecta mandatos de género que en nuestras sociedades han coincidido en exigir a las mujeres comportamientos virtuosos y recato en diversos momentos cotidianos. Viveros (2011) señala que entre las décadas de 1950 y 1990 se perciben "cambios controlados" pues la incursión de las mujeres en el mercado laboral, la conquista del derecho al voto, o el acceso a anticonceptivos no significó transformaciones plenas, por el contrario, en medio de estos cambios se promueve de manera simultánea la idea de la mujer como el baluarte moral del hogar, en donde prima su modestia y evidencia de pudor en todo momento. Viveros (2009) conecta las ideas que se tienen frente a la sexualidad y la racialización, argumentando que la asignación de atributos de inferioridad a la población negra e indígena durante los periodos de dominio de europeos ha dado lugar a formas de disciplinamiento de los cuerpos en donde precisamente los cuerpos racializados, sexualizados encarnados por las mujeres sufren los efectos desproporcionados de la exclusión.

Bajo miradas críticas y de-coloniales las relaciones intersubjetivas permanecen bajo una hegemonía euro centrada, dicha perspectiva del mundo no solo impone un modo de conocer y concebir a los sujetos, sino que tiene afinidades con las ideologías frente a las construcciones de la masculinidad y feminidad; las cuales han asignado valores diferenciados posicionando a los hombres en lugares de privilegio siendo referentes de sujetos a los cuales se les asigna la calidad de fuertes y proveedores. Al 
respecto, Gabriela Castellanos (2006) señala que el género es la forma primaria mediante la cual aprendemos lo que es el poder y, es en el marco de las socializaciones impartidas por las familias que se observa desde la infancia significados en relación a quién manda y quién no.

Haciendo alusión además a los aportes de Foucault (1980) frente a la conceptualización del poder, éste se traduce en una relación que se presenta en todas partes y en esa medida vivimos en medio de cadena de poderes, donde de manera simultánea podemos ocupar lugares de ventaja y desventaja. Así, si en los contextos urbanos, públicos y occidentalizados se discrimina y excluyen las posiciones sociales y culturales de un hombre indígena, pues éste a su vez en su contexto privado (relaciones familiares) puede gozar de mayor reconocimiento y valor material y simbólico con respecto a las mujeres y niñas y niños de su entorno.

Los patrones de poder que han planteado supremacías de clase social, raciales y de género se han encargado de perpetuar la subordinación ejercida sobre las poblaciones descendientes de personas esclavizadas y libertos, asentadas en el país. También la opresión se ha expresado sobre diversos pueblos indígenas y se han consolidado estereotipos bajo los cuales se juzgan las conductas actuales y futuras de mujeres y hombres negras e indígenas. Lo que se hace es producir pensamientos y esquemas "típicos" basados en la información (lectura ideológica) que se extrae del cuerpo.

En el caso de la gente afrodescendiente, su apariencia física provee información sobre sus supuestos atributos psicológicos, morales e intelectuales (Zebrowitz, 1996). Estereotipos asociados a la delincuencia o al consumo de SPA componen parte de aquellas imágenes mentales que en la vida cotidiana se producen en detrimento de las personas. La construcción de imágenes, ideas y concepciones enraizadas en estereotipos que entrelazan consumo y pertenencia étnica dan cuenta de jerarquizaciones; éstas han servido para la invención de un sujeto dominante propio del ideal de modernidad o con las características deseadas por la idea de "progreso"; es decir, un individuo varón, blanco, heterosexual, ilustrado y propietario. Todo aquel por fuera de dichas características es objeto de discriminaciones, entre esas, las que comportan o se derivan de la criminalización de la vida de las personas afrocolombianas. 


\section{Conclusiones}

Cuando se habla de SPA se debe tener en cuenta la historia de las mismas y el lugar que ocupan en un imaginario social según su coyuntura histórica, social, económica y política, pues claramente son variables que influencian las RS, los límites legales e imaginarios que se construyen alrededor del fenómeno. Haber asumido la investigación desde el "paradigma de la interseccionalidad" posibilitó responder a la pregunta de investigación desde una perspectiva más compleja. Se pudo apreciar que las RS que tenía la población acerca del consumo de SPA, se habían construido desde los roles sociales que parten del género y de la pertenencia a un grupo étnico racial. Esto conllevó a que las personas entrevistadas construyeran objetivaciones y anclajes diferenciados hacia algunas ideas y actitudes hacia dicho fenómeno social.

Una dificultad superada en el proceso de investigación, radicó en priorizar el concepto de etnia por sobre el de raza, ya que este último resultaba limitante en la medida en que se refería únicamente a "fenotipos". Mirada "biologicista" que impedía acceder a un análisis integral de las representaciones sociales que tienen las comunidades afrodescendientes e indígenas del Norte del Cauca frente al consumo de SPA.

Estudios desde la perspectiva de género como el llevado a cabo en la Universidad del Valle sede NC, puede aportar a futuros (as) investigadores (as) a retomar el interés por el fenómeno del consumo de SPA en un posible escenario de legalización de las mismas en Colombia. Argumentos expuestos por la Corte Suprema en 2015, en los cuales ratificaron la no judicialización de la "dosis personal" por considerarla un derecho ciudadano, han venido despertando un interesante debate nacional que posiblemente esté dando visos de transformaciones futuras en Colombia sobre la normatividad en materia de SPA, lo que a su vez ocasionaría paulatinamente modificaciones en las representaciones sociales y en las variables que en ellas intervienen, como las mencionadas a lo largo de este documento. La recolección de información cualitativa mostró una importante cantidad de ideas, concepciones e imaginarios que legitiman desigualdades de género al reducir los papeles de las mujeres a escenarios 
domésticos, pudorosos, y virtuosos. Es importante resaltar también aquellas representaciones que parten de procesos de re significación donde las y los estudiantes rompieron con discursos dominantes y propusieron elementos de equidad en las ideas expresadas sobre los papeles de género, pues en sus construcciones se vislumbraron múltiples identificaciones que generaron reflexiones críticas y transformadoras.

Algunos hallazgos mostraron rupturas en las RS, que partían de las experiencias particulares de los y las estudiantes y que significan transiciones en las ideas acerca del género, la etnia y la raza. Probablemente, las generaciones anteriores de sus contextos cercanos consideraron las normas de género y validaron relaciones de género que derivaron en discriminaciones y exclusiones hacia las mujeres y las niñas. La emergencia de nuevas identidades femeninas y masculinas propone cambios en lo público y lo privado, en lo objetivo y lo subjetivo. También esto refiere a la posibilidad de explicarse el mundo desde el orden de lo sociocultural y no desde el ámbito natural o divino.

El cumplimiento de los roles expresivos impuestos a las mujeres ha implicado a lo largo de la historia desempeñar papeles de obediencia y carecer de derechos. Hoy, sin afirmar transformaciones totales al respecto, sí se cuenta con conquistas y avances en materia legal y cultural que las nuevas generaciones adoptan y eligen en sus procesos de individuación. "Servir a un marido" no es una opción para algunas de las estudiantes entrevistadas, en cambio, el cuestionamiento se presenta como oportunidad para el cambio. Apostarle a cambios culturales en relación a cómo se percibe y actúa en materia de género implica cuestionar ejercicios autoritarios del poder, tanto en el espacio público o en el privado. Pensar y hacer lo que se tenga al alcance para transformar desigualdades (relaciones familiares, de pareja, crianza, amistades, entre otras) constituye actos políticos que democratizan la vida cotidiana. Suscribimos así a las reflexiones del sociólogo Boaventura de Sousa Santos cuando plantea que lo cotidiano es el mundo de la intersubjetividad y a la vez una dimensión espacio-temporal habitada por excesos de regulación y opresiones concretas, esto hace que la emancipación por la que se lucha no es sólo política sino ante todo personal, social y cultural (De Sousa, 2001). 


\section{Referencias bibliográficas}

Agamben, G. (2011). ¿Qué es un dispositivo? Revista sociológica, 73(26), 249264. Recuperado de http://www.sociologicamexico.azc.uam.mx/index.php/ Sociologica/article/view/112/103

Cañedo, M. (1999). Cultura e identidad desde la óptica antropológica: una revisión teórica. Thémata. Revista de filosofía, 23, 181-184. Recuperado de http://institucional.us.es/revistas/themata/23/10\%20canedo.pdf

Castellanos, G. (2006). Sexo, género y feminismo. Tres categorías en pugna. Universidad del Valle. Centro de Estudios de Género, Mujer y Sociedad.

Crenshaw, K. (1995). Mapping the margins: Intersectionality, identity politics, and violence against women of color. Stanford Law Review, 43(6), 12411299. Recuperado de http://www.jstor.org/stable/1229039

De Souza, B. (2001). Los nuevos movimientos sociales. Observatorio Social de América Latina (OSAL), 5, 177-188. Recuperado de http://www. boaventuradesousasantos.pt/media/pdfs/Los_nuevos_movimientos_sociales OSAL2001.PDF

Deleuze, G. (1990). Michael Foucault filósofo. Barcelona: Editorial Gedisa.

Durkheim, E. (2012). La división del trabajo social. Madrid: Editorial biblioteca nueva.

Escohotado, A. (1998). Historia de las drogas. Madrid: Alianza Editorial.

Foucault, M. (1980). Power/knowledge. New York: Pantheon Books.

Foucault, M. (2005). La hermenéutica del sujeto. Madrid: Editorial Akal.

Giddens, A. (2000). Sociología. Madrid: Alianza Editorial.

Goffman, E. (1959). La presentación de la persona en la vida cotidiana. Buenos Aires: Amorrortu editores.

Goffman, E. (1963). Behavior in Public Places. Notes on the Social Organization of Gatherings. London: Free Press of Glencoe

Hamilton, D. L. y Trolier, T. K. (1985). Stereotypes and stereotyping: An overview of the cognitive approach. Journal of Personality and Social Psychology, 48

Hewstone, M. y Moscovici, S. (1986). De la ciencia al sentido común. En Moscovici, S. (Comp.) Psicología Social, II. Pensamiento y vida social. Psicología social y problemas sociales. España: Editorial Paidós.

Maffia, D. (2003). Contra las dicotomías: feminismo y epistemología crítica. Buenos Aires: Universidad de Buenos Aires. Instituto Interdisciplinario de Estudios de Género, Recuperado de dianamaffia.com.ar/archivos/contra_las_ dicotomias.doc

Mazzotti, P. (2006). Las drogas, sus implicaciones culturales, políticas y económicas. Fòrum de recerca. España: Universitat Jaume. Recuperado de 
http://repositori.uji.es/xmlui/bitstream/handle/10234/80231/forum_1999_24. pdf? sequence $=1$

Medina, M. E.; Natera, G. y Borges, G. (2001). Del siglo XX al tercer milenio. Las adicciones y la salud pública: Drogas, alcohol y sociedad. Revista salud mental, 24(4), 3-19. Recuperado de http://www.redalyc.org/articulo.oa?id=58242402

Mendoza, A.; Romero, J. F.; Mendoza, G. y Posada, I. (2015). Significados del consumo de sustancias psicoactivas en indígenas estudiantes de una universidad de Medellín, Colombia. Revista Univ. Psychol, 14(3), 975-983. Recuperado de http://revistas.javeriana.edu.co/index.php/revPsycho/article/view/7449/12438 Mora, M (2002). La teoría de las representaciones sociales de Serge Moscovici. Athenea Digital, 2. DOI: https://doi.org/10.5565/rev/athenead/v1n2.55

Parsons, T. (1999). El sistema social. Madrid: Alianza Editorial.

Ritzer, G. (2001). Teoría sociológica moderna. España: Editorial McGrawHill.

Romero, M. F. y Silva, J. S. (2009). Erradicación de cultivos de uso ilícito: fracaso del Plan Colombia y éxito del efecto globo. Cuadernos de Ciencias Jurídicas y Política Internacional. 2(1), 235-252.

UNODC (2009). Evaluación Rápida de la Situación de Consumo de Heroína en el Municipio de Santander de Quilichao, Cauca. Colombia: Universidad Nacional de Colombia. Facultad de Ciencias Humanas. Grupo Antropología Médica Crítica. Recuperado de http://www.odc.gov.co/Portals/1/modPublicaciones/ pdf/CO03392009-evaluacion-rapida-situacion-consumo-heroina-municipiosantander-quilichao-cauca-.pdf

Viveros, M. (2009). La sexualización de la raza y la racialización de la sexualidad en el contexto latinoamericano actual. Revista Latinoamericana de Estudios de Familia, 1, 63-81. Recuperado de http://200.21.104.25/revlatinofamilia/ downloads/Rlef1_4.pdf

Weber, M. (1971). Economía y Sociedad. México: Fondo de Cultura Económica. Zebrowitz, L. (1996). Physical Appearance as a Basis of Stereotyping. In. Macrae, C.; Stangor, C. y Hewstone, M. (eds) Stereotypes and Stereotyping (pp.79120). New York: The Guildford Press.

Cómo citar este artículo:

Blanco-Echeverry, M. (2017). Representaciones sociales ante las sustancias psicoactivas desde un enfoque étnico-racial y de género: un estudio de caso. Prospectiva, 24, 273-301. Doi: 10.25100/ prts.v\%vi\%i.5842 